\title{
Alterations in the expression of IGF-I isoforms and binding proteins during the wound healing process
}

\author{
ZOE GAROUFALIA ${ }^{1}$, ARGYRO PAPADOPETRAKI ${ }^{2}$, DIMITRIOS VARDAKOSTAS ${ }^{1}$, \\ ELLI KARATZA $^{1}$, ANASTASSIOS PHILIPPOU ${ }^{2}$, GERASIMOS TSOUROUFLIS ${ }^{1}$, \\ GREGORY KOURAKLIS $^{1}$ and DIMITRIOS MANTAS ${ }^{1}$ \\ ${ }^{1}$ Second Department of Propaedeutic Surgery, 'Laiko' General Hospital, Medical School, \\ National and Kapodistrian University of Athens; ${ }^{2}$ Department of Physiology, \\ Medical School, National and Kapodistrian University of Athens, 11527 Athens, Greece
}

Received October 31, 2021; Accepted February 28, 2022

DOI: $10.3892 /$ wasj.2022.148

\begin{abstract}
There is increasing evidence to indicate that insulin-like growth factor (IGF)-1 plays a crucial role in the regeneration of different tissues following injury. Notably, despite the escalating number of animal studies, studies investigating the role of IGF-1 in the wound healing process in humans are fewer. In this context, the aim of the present study was to evaluate the variations in the expression IGF-1 isoforms (IGF1-Ea, IGF1-Eb and IGF1-Ec), as well as its binding protein and receptor (IGF-BP3 and IGF-1R) during wound healing in patients. The study population comprised of 21 patients presenting with the first episode of sacrococcygeal pilonidal disease. Samples were obtained during surgery, as well as on days 2,7 and 14 post-operatively. The expression levels of IGF-1 isoforms, as well as that of its binding protein and receptor were evaluated using reverse transcription-quantitative PCR. Statistical analyses were performed using GraphPad Prism software. The Kruskal-Wallis test and Dunn's post hoc test were utilized. The results revealed a statistically significant difference in the expression of IGF-BP3 and IGF-1R during wound healing $(\mathrm{P}=0.014$ and $\mathrm{P}=0.018$, respectively). Specifically, the pairwise post-hoc Dunn test indicated that IGF-BP3 expression was significantly decreased on the 2nd post-operative day compared to the day of surgery, while IGF-1R expression was significantly increased at 14 days post-operatively. The expression of the remaining IGF-1 isoforms was not significantly altered during wound healing. On the whole, as demonstrated herein, IGF-BP3 and IGF-1R appear to play a crucial role during the wound healing process,
\end{abstract}

Correspondence to: Dr Zoe Garoufalia, Second Department of Propaedeutic Surgery, 'Laiko' General Hospital, Medical School, National and Kapodistrian University of Athens, 17 Agiou Thoma Street, 11527 Athens, Greece

E-mail: zoegaroufalia@gmail.com

Key words: anaplasis, chronic ulcers, insulin-like growth factor 1 , tissue regeneration particularly in patients with large open wounds following pilonidal disease treatment. Further studies are warranted to evaluate the exact role, as well as the possible use of these proteins as enhancers of wound healing.

\section{Introduction}

Wound anaplasis is a dynamic, complex process that involves a number of cell types and a variety of biological processes, such as proliferation, differentiation and migration (1). The interactions between these cells are initiated and mediated mostly by growth factors (2-4). One of these factors is insulin-like growth factor (IGF)-1. IGF-1 is a protein with a similar molecular structure to insulin, which has been shown to play a crucial role during growth and exerts several anabolic effects in humans (5). The main secretion of IGF-1 occurs in the liver and is regulated by growth hormone. It is also produced by other organs, such as the skeletal muscle, kidney and brain (6-12). The IGF-1 gene can produce different transcripts through alternative splicing. This phenomenon results in three different IGF-1 transcripts, namely IGF-1Ea, IGF-1Eb and IGF-1Ec, encoding the IGF-1 protein isoforms (6-12).

Approximately $98 \%$ of IGF-1 is always bound to one of six binding proteins (IGF-BP). IGF-BP3 accounts for $80 \%$ of all IGF binding (13). IGF-1 exerts its effects by binding to specific receptors on the cell surface (10). There is increasing evidence to indicate that IGF-1 plays a main role in the regeneration of different tissues following injury (11,14-17). Of note however, despite the escalating number of animal studies (18-20), there are fewer studies investigating the role of IGF-1 in the wound healing process in humans.

In this context, the present study aimed to evaluate the variations in the expression IGF-1 isoforms (IGF1-Ea, IGF1-Eb and IGF1-Ec), as well as its binding protein and receptor (IGF-BP3 and IGF-1R) during wound healing.

\section{Patients and methods}

Patients. A total of 21 patients, presenting with the first episode of sacrococcygeal pilonidal disease were enrolled in the present study, from December, 2017 to December, 2018. 
The samples were obtained at the Laiko University Hospital (Athens, Greece). The present study population was selected due to the presence of an open wound and the possibility of sampling on consecutive days. All patients provided their written consent to participate in the study, which followed the 1975 Helsinki guidelines and was approved by the Bioethical Committee of the Medical School of the National and Kapodistrian University of Athens (13-3-2017/Protocol no. 255). Only adult patients were included in the present study and these were patients with a first episode of pilonidal disease. Tissue samples were obtained during surgery (time 0 ), as well as on day 2, 7 and 14 post-operatively. The days of sampling were selected based on the phases of the healing process, always bearing in mind that different healing phases are not mutually exclusive and tend to overlap.

Tissue specimens. The size of the samples was $0.5 \mathrm{~cm}$ (depth), consisting of full-thickness biopsies of the wound (skin and subcutaneous tissue). Biopsy samples were immediately transferred in Ambion RNAlater (Thermo Fisher Scientific Inc.) and rozen on site at $-80^{\circ} \mathrm{C}$.

RNA isolation and cDNA synthesis. Once all tissues were collected, RNA extraction was performed. Total RNA was extracted from the tissue samples using the TRItidy protocol (TRItidy $G^{\mathrm{TM}}$ reagent, PanReac AppliChem). According to this protocol, the total RNA was obtained in the aqueous phase during the acidic extraction. Following RNA isolation, reverse transcription reaction was performed using the standard protocol of the Protoscript II First Strand cDNA synthesis kit [ProtoScript ${ }^{\circledR}$ II First Strand cDNA Synthesis kit (\#E6560L; New England BioLabs, Inc.)].

Reverse transcription-quantitative polymerase chain reaction $(R T-q P C R)$. In total, five sets of primers (Table I) were used to amplify five different target mRNAs, IGF1-Ea, IGF1-Eb, IGF1-Ec, IGF-BP3 and IGF-1R. 18S ribosomal RNA (rRNA) was used as the housekeeping gene. The samples were amplified using a Thermal Cycler (Bio-Rad iCycler Thermal Cycler IQ5 Multicolor Real-Time PCR Detection System). A negative control with no template was used in each qPCR plate. The samples were amplified using a Thermal Cycler (Bio-Rad iCycler Thermal Cycler IQ5 Multicolor Real-Time PCR Detection System; Bio-Rad Laboratories, Inc.) and each PCR reaction had a total volume of $20 \mu \mathrm{l}$ containing $12.5 \mu \mathrm{l} \mathrm{iQ}^{\mathrm{TM}}$ SYBR-Green Supermix (Bio-Rad Laboratories, Inc.), $50 \mathrm{ng}$ cDNA, $0.4 \mu \mathrm{M}$ of each primer and nuclease-free water. The following thermocycling conditions were used: Initial denaturation at $95^{\circ} \mathrm{C}$ for $4 \mathrm{~min}$ followed by 45 cycles of $12 \mathrm{sec}$ at $95^{\circ} \mathrm{C}, 30 \mathrm{sec}$ at $61^{\circ} \mathrm{C}$ for annealing, and $30 \mathrm{sec}$ at $72^{\circ} \mathrm{C}$ for extension. A final extension step was used at $72^{\circ} \mathrm{C}$ for $5 \mathrm{~min}$. In order to quantify and compare the expression levels of each gene between the conditions, was used the automatically calculated number of cycles required for the measured fluorescence to exceed the threshold for detection $(\mathrm{Cq})$. The relative analysis of gene expression data and calculation of $\Delta \Delta \mathrm{Cq}$, was performed according to the well-established $2-\Delta \Delta \mathrm{Ct}$ method, as described elsewhere (21). Each sample was analyzed in duplicate and relative quantification was performed using
Table I. Sequences of the primers used for RT-qPCR.

Gene Primer sequence (5'-3')

$\begin{array}{ll}\text { IGF1-Ea F } & \text { GTGGAGACAGGGGCTTTTATTTC } \\ \text { IGF1-Ea R } & \text { CTTGTTTCCTGCACTCCCTCTACT } \\ \text { IGF1-Eb F } & \text { ATGTCCTCCTCGCATCTCT } \\ \text { IGF1-Eb R } & \text { CCTCCTTCTGTTCCCCTC } \\ \text { IGF1-Ec F } & \text { CGAAGTCTCAGAGAAGGAAAGG } \\ \text { IGF1-Ec R } & \text { ACAGGTAACTCGTGCAGAGC } \\ \text { IGF-1R F } & \text { ACCTCTTCCCCAACCTCAC } \\ \text { IGF-1R R } & \text { CAGGCAGGCACACAGACAC } \\ \text { IGF-BP3 F } & \text { AGTGAGTCGGAGGAGACCGCA } \\ \text { IGF-BP3 R } & \text { CCTTGGTGGTGTAGCCTGGGAGA }\end{array}$

RT-qPCR, reverse transcription-quantitative PCR; IGF, insulin-like growth factor; F, forward; R, reverse.

the housekeeping gene glyceraldehyde 3-phosphate dehydrogenase (GAPDH) as an internal control. The primers used are presented in Table I.

Statistical analysis. The statistical analysis of the results was performed using GraphPad Prism software (GraphPad Prism version 8.0.0 for Windows, GraphPad Software, Inc.; www.graphpad.com). Statistical analysis of relative quantification data $(\Delta \Delta \mathrm{Cq})$ included a non-parametric Kruskal-Wallis test with multiple comparisons of the three timepoints post-surgery compared with baseline (day of surgery) and Dunn's method as a post-hoc test. A P-value $<0.05$ was considered to indicate a statistically significant difference.

\section{Results}

The median age of the study population was 25 years old (range, 18-33 years), with almost 80\% (17/21) being males. No patient had received corticosteroids or any other immunosuppressive medication. All patients had an ASA (American Society of Anesthesiologists) (22) score of I. No antibiotics or other medications were prescribed post-operatively apart from paracetamol. The wound care was performed on a daily basis-with mechanical irrigation with normal saline and simple gauze dressings by the patient or their immediate family members except for the days that they participated in the protocol.

IGF-1 isoforms (IGF1-Ea, IGF1-Eb, IGF1-Ec). The expression of IGF-1 isoforms (IGF-1Ea, IGF-1Eb and IGF-1Ec) was not significantly altered during the process of wound healing in the present study population. All wounds were clean and healing in an expected manner; despite that, no marked differences were noted in the expression of these growth factors (Fig. 1).

$I G F-I-B P 3$. The expression of IGF-BP3 was significantly increased during the post-operative period $(\mathrm{P}=0.014)$ compared 

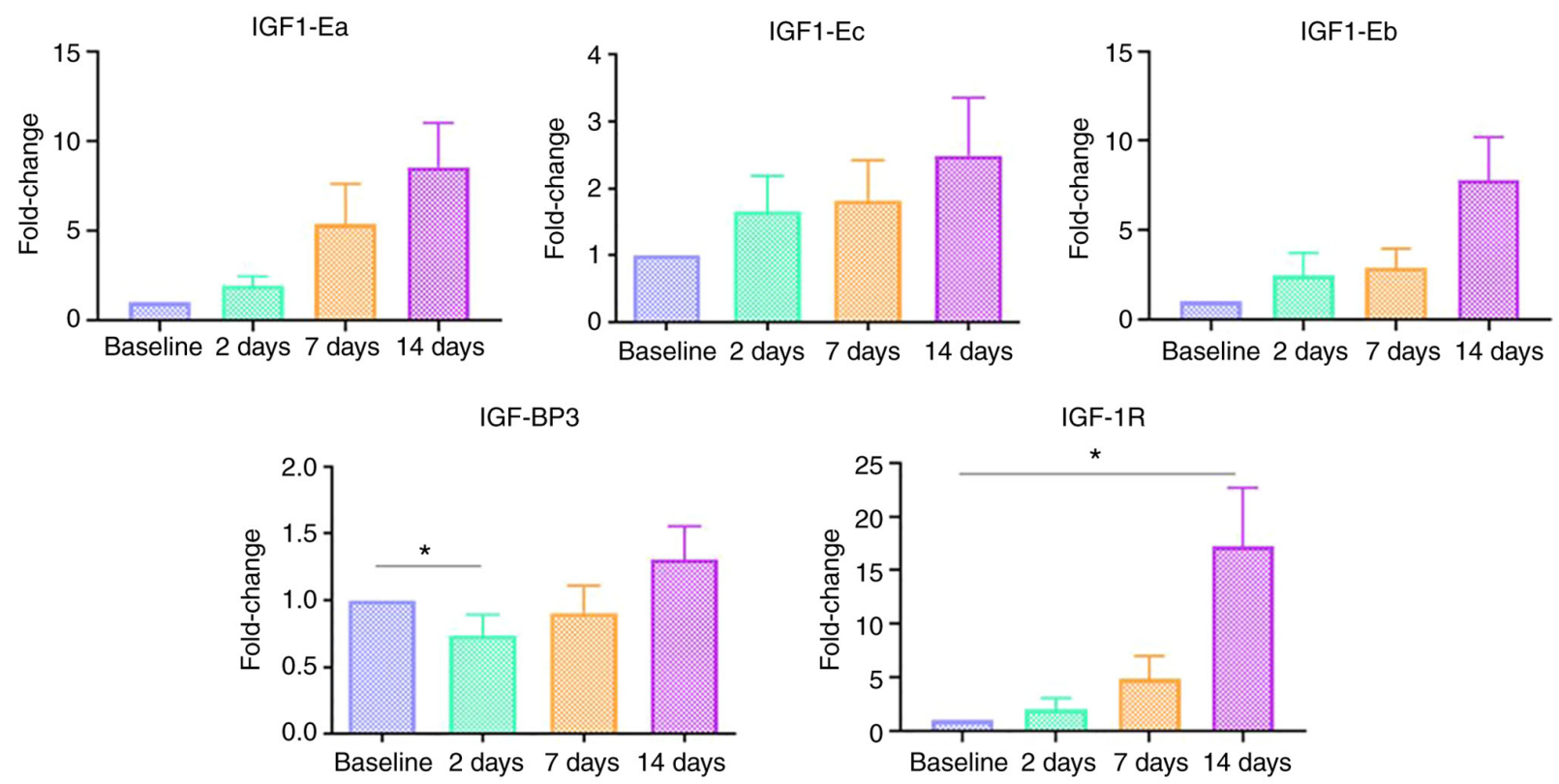

Figure 1. Expression of IGF1-Ea, IGF1-Eb, IGF1-Ec, IGF-BP3 and IGF-1R throughout the 2-week healing period. All data are expressed as fold changes compared to baseline (time 0 ) and represented as the mean $\pm \mathrm{SE}$ ("P<0.05). IGF, insulin-like growth factor.

with the baseline. A pairwise post-hoc Dunn test indicated that it was significantly decreased on day 2 post-operatively compared to the day of surgery (Fig. 1).

$I G F-1 R$. The expression of IGF-1R was also increased post-operatively $(\mathrm{P}=0.018)$, with a significant increase observed on the 14th post-operative day compared to the day of surgery (Fig. 1).

\section{Discussion}

Wound healing is a complex process that occurs in several phases and involves several factors. IGF-1 is a hormone that plays a crucial role during growth and development and is expressed in several tissues in humans where it exerts several anabolic effects $(23,24)$.

Several animal studies have been conducted to assess the role of IGF-1 in the process of wound anaplasis, using both local as well as systemic administration. Lynch et al (3) studied the application of recombinant IGF-I and platelet-derived growth factor-2 in partial thickness wounds, which were surgically induced in the back and thoracic areas of young white Yorkshire pigs. They reported a $132 \%$ increase in the dermal thickness and a $300 \%$ increase in the number of connective tissue cells within the wound site as well as in the collagen content and maturity, following (3). Moreover, a placebo-controlled trial demonstrated that IGF-1 depletion in hypophysectomized rats resulted in a 50\% reduction in wound protein levels and hydroxyproline content, and that when IGF-1 was administered the levels of these variables returned to normal levels (25).

Given the aforementioned findings in animal models, further studies have been performed regarding the optimum means of IGF-I delivery in the wound micro-environment. Jeschke et al (26) concluded that wound anaplasis can be accelerated by liposomal IGF-1 gene transfer. Furthermore, another study reported an improved healing process in collagenous tissue following the systemic administration of IGF-1 in rats (27).

On the other hand, in humans, there is limited information available on the expression of IGF-1 or its different isoforms following trauma and wound healing. Various responses in IGF-1 transcriptional levels have been reported following resistance exercise. As previously demonstrated, following $2.5 \mathrm{~h}$ of resistance exercise, the IGF-1Ea isoform appears to be stable (28), or to be downregulated during the initial part of recovery (up to 2 days after exercise) (29). In addition, the mRNA levels of the IGF-1Eb and IGF-1Ec isoform have been found to be unaffected up to 2 days following exercise (29).

Of note, the present study has several limitations. Firstly, there was no control group, and the intended sample size $(n=30)$ was not reached. In addition, there was no standardized method of estimating the healing process of the wound, which severely restricted the translation of the results. Furthermore, additional experiments, such as western blot analysis and immunohistochemistry were not employed.

In conclusion, IGF-1 is a hormone with profound anabolic activities and a crucial role in wound anaplasis. The IGF-1-induced stimulation of wound healing has been demonstrated in several animal studies. A recent systematic review (30) demonstrated a potentially promising, evidence-based practice favoring the use of IGF-I in addressing patients with large burn wounds, chronic diabetic ulcers, and patients with impaired wound healing. Studying the variations of IGF-1 expression may help in the wound healing process by detecting the solely responsible binding protein and receptor on the cell surface, resulting in most targeted future therapies. Thus, further consistent clinical trials are warranted, focusing on the medical use of recombinant IGF-1 in patients whose healing process has been compromised. 


\section{Acknowledgements}

Not applicable.

\section{Funding}

No funding was received.

\section{Availability of data and materials}

The datasets used and/or analyzed during the current study are available from the corresponding author on reasonable request.

\section{Authors' contributions}

ZG contributed to the experiments and the drafting of the manuscript. APh and APa contributed to the statistical analysis. $\mathrm{APa}, \mathrm{DV}$ and $\mathrm{EK}$ contributed to the experimental process. APh, GT, GK and DM were involved in the conception and design of the study. ZG and DM confirm the authenticity of all raw data. All authors have read and approved the final manuscript.

\section{Ethics approval and consent to participate}

All patients provided their written consent to participate in the study, which followed the 1975 Helsinki guidelines and was approved by the Bioethical Committee of the Medical School of the National and Kapodistrian University of Athens (13-3-2017/Protocol no. 255).

\section{Patient consent for publication}

Not applicable.

\section{Competing interests}

The authors declare that they have no competing interests.

\section{References}

1. Clark RA: Cutaneous tissue repair: Basic biologic considerations I. J Am Acad Dermatol 13: 701-725, 1985.

2. Ksander GA: Chapter 24. Exogenous growth factors in dermal wound healing. Annu Rep Med Chem 24: 223-232, 1989.

3. Lynch SE, Colvin RB and Antoniades HN: Growth factors in wound healing. Single and synergistic effects on partial thickness porcine skin wounds. J Clin Invest 84: 640-646, 1989.

4. Wahl SM, Wong H and Mc-Cartney-Francis N: Role of growth factors in inflammation and repair. J Cell Biochem 40: 193-199, 1989.

5. Rinderknecht $\mathrm{E}$ and Humbel RE: The amino acid sequence of human insulin-like growth factor I and its structural homology with proinsulin. J Biol Chem 253: 2769-2776, 1978.

6. Moschos MM, Armakolas A, Philippou A, Pissimissis N, Panteleakou Z, Nezos A, Kaparelou M and Koutsilieris M: Expression of the insulin-like growth factor 1 (IGF-1) and type I IGF receptor mRNAs in human HLE-B3 lens epithelial cells. In Vivo 25: 179-184, 2011.

7. Milingos DS, Philippou A, Armakolas A, Papageorgiou E, Sourla A, Protopapas A, Liapi A, Antsaklis A, Mastrominas M and Koutsilieris M: Insulinlike growth factor-1Ec (MGF) expression in eutopic and ectopic endometrium: characterization of the MGF E-peptide actions in vitro. Mol Med 17: 21-28, 2011.

8. Stavropoulou A, Halapas A, Sourla A, Philippou A, Papageorgiou E, Papalois A and Koutsilieris M: IGF-1 expression in infarcted myocardium and MGF E peptide actions in rat cardiomyocytes in vitro. Mol Med 15: 127-135, 2009.
9. Durzyńska J, Philippou A, Brisson BK, Nguyen-McCarty M and Barton ER: The pro-forms of insulin-like growth factor I (IGF-I) are predominant in skeletal muscle and alter IGF-I receptor activation. Endocrinology 154: 1215-1224, 2013.

10. Philippou A, Maridaki M, Pneumaticos S and Koutsilieris M: The complexity of the IGF1 gene splicing, posttranslational modification and bioactivity. Mol Med 20: 202-214, 2014.

11. Thomas CG, Psarros C, Gekas A, Vandoros GP, Philippou A and Koutsilieris M: Alternative splicing of IGF1 gene as a potential factor in the pathogenesis of Peyronie's diseas. In Vivo 30: 251-256, 2016.

12. Philippou A, Maridaki M, Halapas A and Koutsilieris M: The role of the insulin-like growth factor 1 (IGF-1) in skeletal muscle physiology. In Vivo 21: 45-54, 2007.

13. Jansen M, van Schaik FM, Ricker AT, Bullock B, Woods DE, Gabbay KH, Nussbaum AL, Sussenbach JS and Van den Brande JL: Sequence of cDNA encoding human insulin-like growth factor I precursor. Nature 306: 609-611, 1983.

14. Karalaki M, Fili S, Philippou A and Koutsilieris M: Muscle regeneration: Cellular and molecular events. In Vivo 23: 779-796, 2009.

15. Philippou A, Papageorgiou E, Bogdanis G, Halapas A, Sourla A, Maridaki M, Pissimissis N and Koutsilieris M: Expression of IGF-1 isoforms after exercise-induced muscle damage in humans: Characterization of the MGF E peptide actions in vitro. In Vivo 23: 567-575, 2009.

16. Philippou A, Halapas A, Maridaki M and Koutsilieris M: Type I insulin-like growth factor receptor signaling in skeletal muscle regeneration and hypertrophy. J Musculoskelet Neuronal Interact 7: 208-218, 2007.

17. Bhora FY, Dunkin BJ, Batzri S, Aly HM, Bass BL, Sidawy AN and Harmon JW: Effect of growth factors on cell proliferation and epithelialization in human skin. J Surg Res 59: 236-244, 1995.

18. Kanje M, Skottner A, Sjöberg J and Lundborg G: Insulin-like growth factor I (IGF-I) stimulates regeneration of the rat sciatic nerve. Brain Res 486: 396-398, 1989.

19. Sjöberg J and Kanje M: Insulin-like growth factor (IGF-1) as a stimulator of regeneration in the freeze-injured rat sciatic nerve. Brain Res 485: 102-108, 1989.

20. LeRoith D: Clinical relevance of systemic and local IGF-I: Lessons from animal models. Pediatr Endocrinol Rev 5 (Suppl 2): S739-S743, 2008.

21. Livak KJ and Schmittgen TD: Analysis of relative gene expression data using real-time quantitative PCR and the 2(-Delta Delta C(T)) method. Methods 25: 402-408, 2001.

22. American Society of Anesthesiologists ASA): ASA Physical Status Classification System. ASA, Washington, DC, 2020. https://www. asahq.org/standards-and-guidelines/asa-physical-status-classification-system. Accessed February 22, 2022.

23. Baker J, Liu JP, Robertson EJ and Efstratiadis A: Role of insulin-like growth factors in embryonic and postnatal growth. Cell 75: 73-82, 1993

24. Daughaday WH and Rotwein P: Insulin-like growth factors I and II. Peptide, messenger ribonucleic acid and gene structures, serum, and tissue concentrations. Endocr Rev 10: 68-91, 1989.

25. Mueller RV, Hunt TK, Tokunaga A and Spencer EM: The effect of insulinlike growth factor I on wound healing variables and macrophages in rats. Arch Surg 129: 262-265, 1994.

26. Jeschke MG, Schubert T, Krickhahn M, Polykandriotis E, Klein D, Perez-Polo JR, Przkora R and Herndon DN: Interaction of exogenous liposomal insulin-like growth factor-I cDNA gene transfer with growth factors on collagen expression in acute wounds. Wound Repair Regen 13: 269-277, 2005.

27. Provenzano PP, Alejandro-Osorio AL, Grorud KW, Martinez DA, Vailas AC, Grindeland RE and Vanderby R Jr: Systemic administration of IGF-I enhances healing in collagenous extracellular matrices: Evaluation of loaded and unloaded ligaments. BMC Physiol 7: 2, 2007.

28. Hameed M, Orrell RW, Cobbold M, Goldspink G and Harridge SD: Expression of IGF-I splice variants in young and old human skeletal muscle after high resistance exercise. J Physiol 547: 247-254, 2003.

29. Psilander N, Damsgaard R and Pilegaard H: Resistance exercise alters MRF and IGF-I mRNA content in human skeletal muscle. J Appl Physiol (1985) 95: 1038-1044, 2003.

30. Garoufalia Z, Papadopetraki A, Karatza E, Vardakostas D, Philippou A, Kouraklis G and Mantas D: Insulin-like growth factor-I and wound healing, a potential answer to non-healing wounds: A systematic review of the literature and future perspectives. Biomed Rep 15: 66, 2021. 